\title{
Sustainable Agricultural Practices, Farm Income and Food Security among Rural Households in Africa
}

Abdul-Hanan Abdallah ( $\nabla$ abdallahabdulhanan@gmail.com )

University for Development Studies https://orcid.org/0000-0002-2469-0275

Awal Abdul-Rahman

University for Development Studies

Gazali Issahaku

University for Development Studies

\section{Research Article}

Keywords: Sustainable agricultural practices, Farm income, Food security, Multinomial endogenous treatment effects model, Africa

Posted Date: April 15th, 2021

DOI: https://doi.org/10.21203/rs.3.rs-330019/v1

License: () (i) This work is licensed under a Creative Commons Attribution 4.0 International License. Read Full License

Version of Record: A version of this preprint was published at Environment, Development and Sustainability on April 17th, 2021. See the published version at https://doi.org/10.1007/s10668-021-01407-y. 


\section{Abstract}

Sustainable agriculture has been recognized in the literature as one of the important pathways to ensuring food systems and livelihoods among rural households in Africa. Using data from the 'Intensification of Food Crops Agriculture in Sub-Saharan Africa (Afrint)' project, we examine the impact of adoption of multiple sustainable agricultural practices (SAPS) - zero-tillage, intercropping, residue incorporation and animal manure - on farm incomes and food security (captures as self-sufficiency in food production-SSF) among African rural households. Multinomial endogenous treatment effect (METE) method is applied to control potential selection bias. In addition, the multivalued treatment effects (MTE) model and dose-response-functions (DRFs) are also used to examine the treatment effects heterogeneity associated with SAPs adoption. The study reveals that joint adoption of SAPs is increased farm income and food security relative to the adoption of a single practice. Households obtain significantly higher farm income (FI) and food security (FS) via adoption of at least three practices relative to households adopting less than three practices. These findings reaffirm the benefits of adopting SAPs as a package rather than single practice, to enable farm households to derive significant welfare benefits.

\section{Introduction}

Sustainable agriculture is an important aspect of the food system that plays a vital role in enhancing farm incomes and household food security, especially in developing countries (Zero Hunger Challenge, 2016). Achieving sustainable household food production in Africa is however beset with numerous challenges. One of such challenges is decreased farm sizes resulting from increasing pressure from rapid population growth (Barbier \& Hochard, 2018). Another challenge is degraded environment caused by the adverse impacts of climate change, continuous cultivation of soil, poor recycling of organic matter and low-level adoption of soil improvement measures. These challenges, together with institutional and infrastructural bottlenecks lead to poor yields, lower farm incomes, food insecurity and poverty (Dillon \& Barrett, 2017; Teklewold, Kassie, Shiferaw, \& Köhlin, 2013).

One way of maintaining quality of the environment and improving crop yields, farm incomes and food security at the same time is the application of sustainable agricultural practices (SAPs) in food crop production. There is a growing literature on various aspects of sustainable agriculture, from adoption to impacts of adoption of these practices. For instance, Issahaku and Abdulai, (2019) examined the effect of adoption of SAPs in Ghana, and found that adoption has a correlation with food security. Morugán-Coronado et al. (2020) recently showed that various combinations of sustainable agricultural practices (SAPs) including minimum tillage, use of organic fertilizers and alley cropping resulted in positive crop yield response, as well as soil organic carbon and nitrogen accumulation. Generally, SAPs have been defined to include (a) application of manure, crop rotation, integrated pest control (IPM) practices, management-intensive grazing, tillage, residue retention and weed control, (b) the reduced or zero use of petroleum-based products, fertilizers, pesticides, growth stimulators, and antibiotics or a combination of these practices (D'Souza, Cyphers, \& Phipps, 1993).

These practices have been noted to increase soil fertility and organic matter via reduced run-offs and surface temperatures, improve soil moisture, and increase availability of plant nutrients (Kassie, Teklewold, \& Jaleta, 2015; Manda, Alene, Gardebroek, Kassie, \& Tembo, 2016). For these reasons, governments and development practitioners continue to promote SAPs among smallholder farmers to help sustain their livelihoods, while saving the environment (Fontes, 2020; Teklewold, Kassie, \& Shiferaw, 2013). Under the Comprehensive Africa Agriculture Program (CAADP) for instance, adoption of soil and water improving techniques remain a strong pillar promoted by African government and development practitioners (NEPAD, 2003). Also, the Malabo Declaration reemphasized the need to pursue the principles of the CAADP to promote take-up of SAPs in Africa (AU Summit-Malabo, 2014). However, evidence on the adoption and farm income and food security effects of SAPs in a cross-regional context is limited in the empirical literature. Few studies considered adoption and impacts of SAPs across Africa (Abdallah, Abdul-Rahaman, \& Issahaku, 2020; Kassie et al., 2015; Kirui \& Mirzabaev, 2015; Tambo \& Mockshell, 2018). The current study varies from these studies in terms of the types of SAPs and household outcomes being investigated. In addition, this study captures data across different regions of Africa including West, East and Southern Africa. The study adds to the existing studies on sustainable agriculture by assessing the impact of SAPs on farm income (FI) and food security (FS) in West, East and Southern Africa. The SAPs considered are intercropping, zero-tillage, residue incorporation and animal manure use. These practices have been noted to be very useful in enhancing soil fertility, pest control, weed suppression, provision of ecosystem services and consequently safer environment (Kassie et al., 2015).

It is important to highlight possible links between the sustainable agricultural practice adoption and FI and FS. For instance, the SAPs may enhance farm incomes and household food security through increased farm productivity for farm households. Conversely, higher FI and better FS status may motivate farm households' adoption of SAPs. It is also worth mentioning that the adopters of SAPs may systematically differ from non-adopters, and this may be attributable to unobserved heterogeneity. For this reason, a multiple-choice endogenous treatment effect was employed to simultaneously estimate the adoption and impacts of SAPs on FI and FS, and to mitigate the possible selection bias from observable and unobservable factors. In addition, the multivalued treatment effects (MTE) model (Cattaneo, 2010) and dose-response-functions (DRFs) (Guardabascio \& Ventura, 2014) are used to examine the treatment effects heterogeneity associated with the adoption of SAPs.

The rest of the paper is structured as follows. In section two, the literature review on the adoption SAPs in Africa is presented, highlighting the gaps and the contribution of the current study. Section three presents the materials and methods while section four presents the results. In section five, the results are discussed. Sections six and seven present the policy and managerial implications and the conclusions, respectively.

\section{Literature Review}

Aside being resource conserving, sustainable agriculture practices (SAPs) are environmentally friendly and economically viable (FAO, 1989). Thus, it is strongly believed that adoption of SAPs can restore and sustain the use of degraded natural resources and their ecosystem functions as well as enhance yields, income, and food security in Africa. Jack (2013) for instance believed that agricultural innovations could increase yields in Africa. The study by Annan and Dryden (2015) indicated that small-scale producers can feed Africa if the continents' smallholder farmers adopt good agronomic practices with seeds and 
fertilizer. In view of Sanz et al. (2017), adoption of agricultural technologies can increase and sustain farm productivity. In line with these views, alternative SAPs have been promoted by governments and international donors for adoption and welfare improvement of rural households in Africa (FAO, 1989; NEPAD, 2003). However, in promoting adoption of SAPs in Africa, empirical knowledge of the factors influencing the adoption and impacts is relevant for policymakers and development practitioners. Yet most adoption studies have often tended to be country specific (e.g., Abdallah, 2017; D'Souza et al., 1993; Ehiakpor, Danso-Abbeam, \& Mubashiru, 2020; Issahaku \& Abdulai, 2019; Kassie et al., 2015; Kirui \& Mirzabaev, 2015; Makate, Makate, \& Mango, 2017; Manda et al., 2016; Sardar, Kiani, \& Kuslu, 2020; Teklewold, Kassie, \& Shiferaw, 2013; Teklewold, Kassie, Shiferaw, et al., 2013). Moreover, findings from some of these studies - though showed positive impact of SAPs on households - varied from location to location and cannot be generalized to any of the regions of Africa or Africa as a whole, and thus suggest the need for a study that considers the various regions of Africa. The few studies that analysed adoption and impacts of SAPs from multiple locations include Kassie et al. (2015), Kirui \& Mirzabaev (2015), Tambo and Mockshell (2018) and Abdallah et al. (2020). However, the studies by Kassie et al. (2015) and Kirui \& Mirzabaev (2015) focused on East and Southern Africa. Moreover, these studies (i.e., Kassie et al., 2015; Kirui \& Mirzabaev, 2015) focused mainly on factors influencing the adoption of SAPs and hence did not rigorously analyse the impacts of SAPs in Africa. On the other hand, Abdallah et al. (2020) focused on the impacts of SAPs on hidden hunger and total value of output (measured as monetary value of farm produce) while Tambo and Mockshell (2018) focused on household income. Thus, none of these studies analysed the impacts of SAPs on farm income (FI) and food security (FS) even though FI and FS are the major targets for the promotion of SAPs in Africa (Lele et al., 2016; Zero Hunger Challenge, 2016)

By way of filling these gaps highlighted in the literature, this study analyses the impacts of single and joint adoption of SAPs on FI and FS among rural households in Africa. Unlike the previous studies, this study relies on large dataset from three regions of Africa - Southern Africa: Malawi, Zambia and Mozambique; Eastern Africa: Kenya, Ethiopia, Tanzania and Uganda; and West Africa: Ghana and Nigeria - for the analysis. Findings from such a crossregional study could be relevant for policymakers and development practitioners alike in designing strategies that will promote holistic adoption of SAPs in Africa.

\section{Materials And Methods}

In this section, the conceptual framework, estimation strategies and data information are presented. The conceptual framework describes how key institutional, policy, socioeconomic and cultural factors, resources endowments, and social networks could influence the adoption of SAPs and how these variables interact with SAPs to improve farm income and food security (Figure 1). The conceptual relationships between institutional, policy, socioeconomic and cultural factors, resources endowments, social networks and adoption of SAPs were derived from the empirical literature on adoption (Abdul-Rahaman et al., 2021; Sardar et al., 2020; Tambo \& Mockshell, 2018), and from the random utility theory on technology adoption (Di Falco \& Veronesi, 2014; Imbens \& Wooldridge, 2009). On the other hand, the estimation strategies present information regarding the methods employed for the data analysis, and to achieve each of the objectives of this study. The estimation strategies include the multinomial endogenous treatment effects model, the multivalued treatment effects and the dose-response function. The data information covers research location in Africa, units of analysis, sampling and variables employed for the analysis.

\subsection{Conceptual Framework}

Figure 1 illustrates the conceptual framework linking adoption of SAPs to farm income (FI) and food security (FS). The framework conceptualizes how environmental and farm level factors including rainfall, temperature, climatic shocks, declining soil fertility, poor soil aeration, insufficient recycling of organic matter, land degradation, etc. At the farm level, the products of these challenges are reflected in low yields, decreased FI and FS. However, evidence has shown that these challenges can be mitigated through adoption of SAPs including intercropping, zero-tillage, residue incorporation and animal manure and their combinations (Annan \& Dryden, 2015; FAO, 1989; Jack, 2013; Manda et al., 2016; Sanz et al., 2017; Teklewold, Kassie, \& Shiferaw, 2013). Thus, the zeal to mitigate the challenges and as well increase farm yields will lead to single and joint adoption of SAPs among African farm households (Abdallah et al., 2020). However, several variables classified under policy interventions, institutional conditions, socioeconomic and cultural factors, natural resource endowment, social networks (Binswanger \& Pingali, 1988; Erenstein, 2006; Feder, Just, \& Zilberman, 1985) generally influence these adoption decisions of households in Africa. It is important to mention that aside adoption of SAPs, households may also resort to non-farm employment to improve adoption of SAPs and to curtail the negative impact of reduced yields, FI and FS (Abdulai, 2018). However, for purpose of brevity, these dynamics are not captured in Figure 1[1]. Consequently, the adoption of SAPs may then enhance household welfare including FI and FS through increased yields. But welfare may also be influenced by the policy interventions, institutional conditions, socioeconomic and cultural factors, natural resource endowment and social networks mentioned previously or interaction of these factors (Abdallah et al., 2020; Abdulai, 2018; FAO, 1989; Issahaku \& Abdulai, 2019; Jack, 2013; Sanz et al., 2017).

The dynamics explained and captured in Figure 1 may also differ between different regions of Africa, and may also be conceptualized in this study using the theory of random utility (Greene, 2002). Within the framework of random utility, it is assumed that households choose from a package of 16 SAPs, a single or multiple SAPs that maximise their utility.

Assume that farmers consider the net utility $\left(U^{*}\right)$ obtained in choosing alternative combination of SAPs. Specifically, assuming a set of $N$ possible SAPs, the household ${ }^{i}$ chooses practice $j$ over any alternative practice $m$ if utility $U_{i j}$, associated with choosing practice $j$ is greater than the utility $U_{i m}$, associated with the choice of practice $m$. However, $U^{*}$ is latent and cannot be directly observed by the researcher, but can be linked to index of several factors $\left({ }^{Z_{i}}\right)$ including household, farm, location characteristics and choice attributes as:

$U_{i j}^{*}=\alpha_{j} z_{i}+\varepsilon_{i j}$

(1),

where $\alpha_{j}$ is vector of coefficients to be determined and $\varepsilon_{i j}$ is the independent and identically distributed error term. Though $U_{i j}^{*}$ is unobservable, the household's choice of SAPs is observable. Let $A$ be the index of farmers' choice of practice $j$ from SAPs and $A=j$, only and only if $U_{i j}=\max \left(u_{1}, u_{2}, \ldots, u_{N}\right)$; where $u_{i}$ is the utility associated with a particular choice from the package of SAPs under consideration. The multinomial logit regression can be employed to model household adoption of various choices as:

Page 3/13 
$\operatorname{Pr}\left(A_{i}=j\right)=\frac{\exp \left(\alpha_{j} Z_{i}\right)}{\sum_{i=1}^{N} \exp \left(\alpha_{k} Z_{i}\right)}, j=0,1,2,3, \ldots, 16 \quad j \neq k_{(2)}$

Where $A_{i}$ is the index of adoption of SAPs; $\operatorname{Pr}\left(A_{i}=j\right)$ refers to the probability of adopting SAP j among a package of 16 alternative combinations of SAPs shown in Table $1 ; z_{i}, \alpha_{j}$ and $\varepsilon_{i j}$ are as defined earlier.

To link households' choice of SAPs with the outcomes of interest in this study (i.e., FI and FS), the variable $Q$ assumed to be the outcome of interest, is expressed as a function of households' choice of SAPs $\left({ }^{A}\right)$ and other characteristics ${ }^{x}$ as follows:

$Q_{i}=\alpha x_{i}+\beta A_{i}+u_{i}$

Where ${ }^{\alpha}$ and $\beta$ are parameters to be determined and $u_{i}$ is a random error term. If equation 3 is to be estimated using ordinary least squares (OLS), $\beta$ will represent the FI and FS impact of SAPs. However, there is problem of potential selection bias since a farmer's decision to adopt any combination of SAP is self-determined. This implies that unobserved factors may influence both choice of SAPs and outcomes of interest (FI and FS), resulting in a correlation between ${ }^{\varepsilon_{i}}$ in Equation 1 and $u_{i}$ in Equation 3 i.e., ${ }^{c o r r}\left(\varepsilon_{i}, u_{i}\right) \neq 0$. This will lead to a bias estimation of $\alpha$ and $\beta$ (Imbens \& Wooldridge, 2009). In an experimental study, this problem is solved by comparing pretreatment outcomes of households to their treatment outcomes; the difference then becomes the impact of the treatment. However, in nonrandomized studies, such as the present one, such comparison is not possible because of nonrandom assignment of households to treatments. To solve this, several methods have been proposed in the literature (e.g., Bourguignon, Fournier, \& Gurgand, 2007; Cattaneo, 2010; Deb \& Trivedi, 2006). In this study, a multiple-choice endogenous treatment effect method of Deb and Trivedi (2006) is employed to estimate impact of adoption in a polychotomous choice context while accounting for selection bias associated with observable and unobservable factors. Although the method proposed by Bourguignon et al. (2007) could equally be used to carry out such task, it has been observed to be computationally tedious, especially, in cases of estimating the impact of multiple SAPs (e.g., Manda et al., 2016). In addition, the augmented inverse probability weighing estimator of multivalued treatment effects model (Cattaneo, 2010) and the doseresponse function (Guardabascio \& Ventura, 2014) were estimated for robustness checks.

\subsection{Estimation Strategies}

As indicated earlier, the multinomial endogenous treatment effects model, the multivalued treatment effects (MTE) and dose-response function (DRF) were employed for the analysis. The main estimation strategy is the multinomial endogenous treatment effects model, which is presented in the next section. On the other hand, the multivalued treatment effects (MTE) and dose-response function (DRF) were estimated for robustness checks. The methods of MTE and DRF are however not presented here due to space limitation but are available upon requests.

\subsubsection{Multinomial endogenous treatment effect model (METE)}

The METE model by (Deb \& Trivedi, 2006) has a two-stage estimation procedure. In the first stage, the factors influencing choice of SAPs are estimated as:

$\operatorname{Pr}\left(d_{i} \mid Z_{i}, l_{i}\right)=g\left(\alpha_{1} z_{i+} \delta_{1} l_{i 1}, \alpha_{1} z_{i}+\delta_{2} l_{i 2}+\alpha_{J} z_{J}+\delta_{J} l_{i J}\right.$

where ${ }^{d_{i}}$ is a package of SAPs defined as $\mathbf{d}_{\mathbf{i}}=\left(d_{i_{1}}, d_{i_{2},}, d_{i_{3}}, \ldots, d_{i J}\right)$ with $d_{j}$ as dichotomous variables representing the observed choice; ${ }_{i}$ is the household and choice attributes; $\mathbf{l}_{\mathbf{i}}=\left(l_{i_{1}} l_{i_{2}}, l_{i_{3}}, \ldots, l_{i J}\right)$ is the index of unobserved characteristics of household for choosing a particular practice and ${ }^{l_{i j}{ }^{\prime} s}$ are unobserved components of $l_{i} ; \alpha_{j}$ and $\delta_{i}$ the respective coefficients of ${ }^{z_{i}}$ and ${ }^{l_{i j}}$; and $\varepsilon_{i j}$ is the error term assumed to have no influence on $l_{i j}$ and follow independent and identical distribution; and $j=0$ is the non-adopters of any of the SAPs in this study. Further, $g$ is assumed to have a probability that is multinomially distributed (Deb \& Trivedi, 2006) and mathematically stated as:

$\operatorname{Pr}\left(\mathbf{d}_{\mathbf{i}} \mid \mathbf{z}_{\mathbf{i}}, \mathbf{l}_{\mathbf{i}}\right)=\frac{\exp \left(\alpha_{j} z_{i}+\delta_{j} l_{i j}\right)}{1+\sum_{k=1}^{J} \exp \left(\alpha_{k} z_{i}+\delta_{k} l_{i k}\right)}$

For the last stage, the equation for FI and FS impact of household's choice of SAPs is specified as:

$E\left(Q_{i} \mid d_{i}, x_{i}, l_{i}\right)=\beta x_{i}+\sum_{j=1}^{J} \gamma_{j} d_{i j}+\sum_{j=1}^{J} \lambda_{j} l_{i j}$

where ${ }^{x_{i}}$ is an index of covariates influencing the outcome $Q_{;} \beta$ and $\gamma_{j}$ are coefficients to be determined. Further, ${ }_{i j}$ in equation (6) shows that unobservable factors influence the choice of SAPs and outcomes (i.e., FI and FS). According to Deb and Trivedi (2006), the choice of the practices is either directly or inversely correlated with outcomes through the parameter $\lambda_{j}$ of the unobserved variable $l_{i j}$. Thus, a positive (negative) sign of the parameter $\lambda_{j}$ further implies positive (negative) selection bias. The selection and outcome models are estimated jointly using the maximum simulated likelihood method. The METE model is identified using instruments such as farmer perception of SAPs, extension service and membership in farmer-based organization. These instruments are intuitively expected to influence outcomes indirectly through adoption of SAPs. A few studies have employed similar variables as instruments in technology adoption studies (e.g., Di Falco \& Veronesi, 2014).

\subsection{Data information}

The data employed are obtained from the second-round survey of the sub-Saharan Africa intensification of food crops agriculturehereinafter referred to as Afrint II. Afrint II was conducted between 2007 and 2010 through multistage sampling procedure. The first 
stage involved selection of nine countries based on production potential of maize, rice, sorghum and cassava. The second stage involved selection of two or more regions from each country based on agroecological differences. The regions and countries include Eastern and Upper East regions of Ghana; Kakamega and Nyeri of Kenya; Ntchisi, Thiwi, Bwanje and Shire of Malawi; Kaduna and Osun of Nigeria; Bako, Yetmen, Bekoji and Assebot of Ethiopia; North, Centre and South of Mozambique; Kilombero and Iringa of Tanzania; Eastern, Central, South Western, North Western and West Nile of Uganda; and Mkushi and Mazabukaof Zambia (Figure 2). In the third stage, 2-10 communities within regions were selected based on resource endowment. The final stage involved random selection of $300-400$ households from each community. The data used for this study include 3,809 households across nine countries reclassified as West, East and Southern Africa. In the present study, four sustainable agricultural practices and their combinations yielded sixteen adoption categories (see Table 1). As shown in Table 1, about $17 \%$ did not adopt any of the practices for production $\left(I_{0} Z_{0} R_{0} A_{0}\right)$, while $2-5 \%$ simultaneously adopted $3-4 \%$ SAPs.

As stated earlier, FI and FS are the outcomes of interest in this study. Income from the sale of all crops, leasing machines and agricultural wage labor (all measured in USD) was summed to obtain FI for each household. The average FI per household is USD371.12/ha for the pooled sample (see Table 2). With respect to the FS measurement, the household self-sufficiency in food (SSF) was used as a proxy. SSF captures the share of the total food produced and available for household's own consumption, excluding stock changes (Thomson \& Metz, 1998). The SSF was used to capture FS because in rural Africa, where agricultural production is the main livelihood activity and food purchases are constrained by lack of access to markets (Pieters et al., 2013; WFP, 2009), FS is strongly linked to own production available for household's consumption (Thomson \& Metz, 1998). Following Jolly and Gadbois, (1996), the selfsufficiency in food production (SSF) was computed as:

$S S F=\frac{\text { Total cercal }}{\text { Houschold size }}$

From the survey data, both total cereals produced and purchased, as well as household size were gathered for the computation of the SSF. The total available cereal is expressed as, where is the maize equivalent for total refined cereals[2]. refers to the purchased cash crops (e.g., cotton, groundnut, cowpea, and other legumes) in maize equivalent. A threshold of $200 \mathrm{~kg}$ of cereal per annual equivalent recommended by FAO, was used (e.g., Jolly \& Gadbois, 1996). Thus, a household is self-sufficient if the computed SSF is greater or equal to $200 \mathrm{~kg}$ (i.e., household will then be said to be food secured) and food insecure if the SSF value is less than $200 \mathrm{~kg}$. As shown in Table 2, all households are found to be self-sufficient in production, as the average self-sufficiency exceeds the $200 \mathrm{~kg}$ of cereal per annual equivalent, indicating that most households in our sample are food secured.

Following the literature on agricultural technology adoption, data on various household, farm, location and institutional variables influencing adoption or the outcome variables were captured for the present analysis. Table 2 also shows that these variables differ across all locations in the sample. Table 3 also shows mean differences among these variables by adoption of SAPs.

Table 1: Package of SAPs used by Households

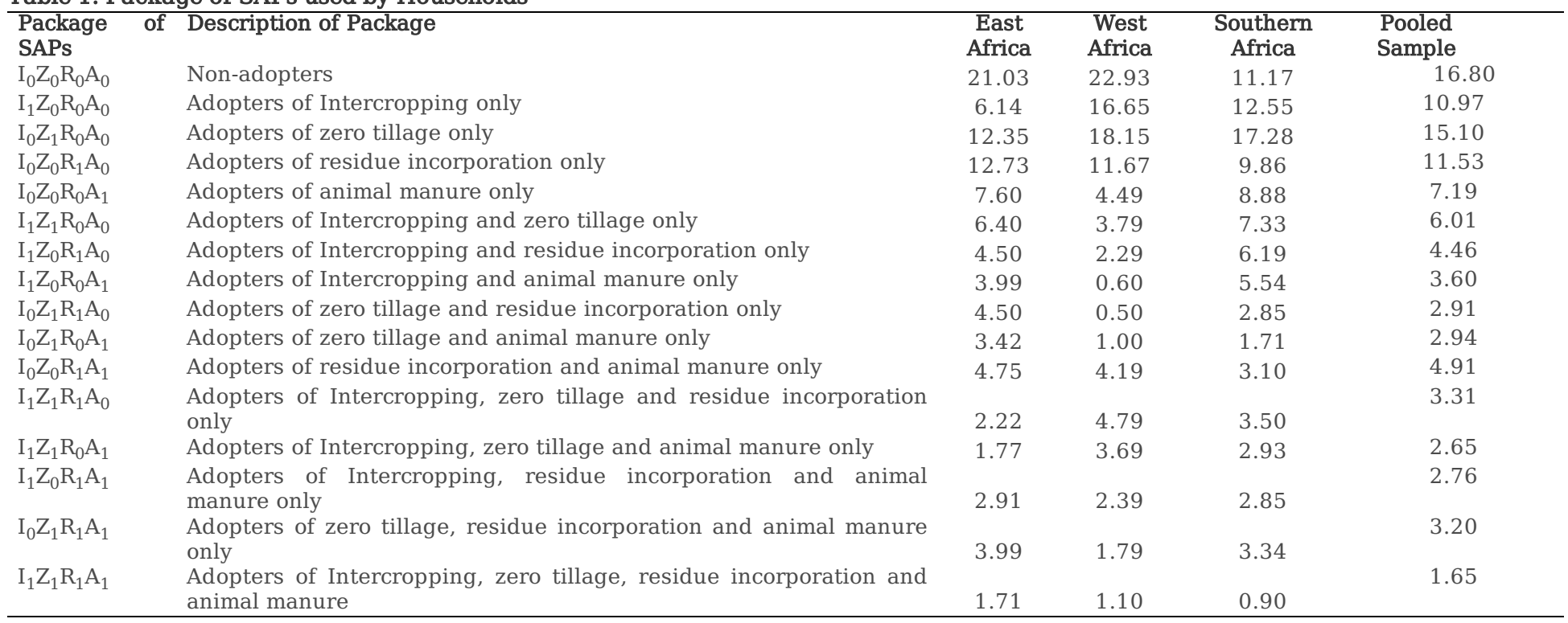

Note: Each element in the choice plan is a binary variable forintercropping with nitrogen fixing crops (I), zero/no tillage (Z), residue incorporation (R) and animal manure (A). Subscript $1=$ adoption and $0=$ otherwise.

Table 2: Descriptive Statistics by Region 


\begin{tabular}{|c|c|c|c|c|c|}
\hline ariable & Descriptions/measurement & East Africa & $\begin{array}{l}\text { West } \\
\text { Africa }\end{array}$ & $\begin{array}{c}\text { Southern } \\
\text { Africa }\end{array}$ & Pooled \\
\hline & \multicolumn{5}{|l|}{ Dependent variables } \\
\hline [ & $\begin{array}{l}\text { Farm income -Sum of the monetary value from sale of crops, leasing machines and } \\
\text { agricultural wage labor (USD/ha) }\end{array}$ & $\begin{array}{c}382.60 \\
(680.40)\end{array}$ & $\begin{array}{c}372.29 \\
(637.60)\end{array}$ & $\begin{array}{c}355.37 \\
(641.63)\end{array}$ & $\begin{array}{c}371.12 \\
(656.88)\end{array}$ \\
\hline \multirow[t]{2}{*}{$\overline{\mathrm{SF}}$} & $\begin{array}{l}\text { Self-sufficiency in food production - share of the total grain produced and available } \\
\text { for household's own consumption }(\mathrm{kg} / \mathrm{ha})\end{array}$ & $\begin{array}{c}340.64 \\
(766.55)\end{array}$ & $\begin{array}{c}394.90 \\
(825.45)\end{array}$ & $301.50(694.64)$ & $\begin{array}{c}342.24 \\
(761.07)\end{array}$ \\
\hline & \multicolumn{5}{|l|}{$\begin{array}{ll} & \text { Household level covariates }\end{array}$} \\
\hline ender & Gender of household head (1 if male; 0 if female) & $0.59(0.49)$ & $0.66(0.47)$ & $0.50(0.50)$ & $0.58(0.49)$ \\
\hline ge & Age of the head of the household (years) & $47.94(14.57)$ & $\begin{array}{c}51.53 \\
(14.56)\end{array}$ & $47.00(14.83)$ & $48.59(14.76)$ \\
\hline ducation & Education of head (years) & $2.59(3.78)$ & $2.64(4.54)$ & $3.43(3.60)$ & $2.88(3.96)$ \\
\hline $\begin{array}{l}\text { ousehold } \\
\text { ze }\end{array}$ & Number of members & $5.76(3.97)$ & $\begin{array}{c}5.33 \\
(3.55)\end{array}$ & $6.65(4.40)$ & $5.93(4.04)$ \\
\hline $\begin{array}{l}\text { ff-farm } \\
\text { come }\end{array}$ & $\begin{array}{l}\text { Aggregate income from wage-employment, nonfarm self-employment, property } \\
\text { income, pensions, and remittances }\end{array}$ & 173.02(588.91) & $\begin{array}{c}207.93 \\
(472.44) \\
\end{array}$ & 149.73(384.73) & $174.71(500.59)$ \\
\hline \multirow[t]{2}{*}{ ligrate } & Dummy ( 1 if any member migrated to another area; 0 if otherwise) & $0.63(0.48)$ & $0.45(0.50)$ & $0.52(0.50)$ & $0.55(0.50)$ \\
\hline & \multicolumn{5}{|l|}{$\begin{array}{ll} & \text { Plot level covariates }\end{array}$} \\
\hline arm size & Total cultivated area (hectares) & $4.16(6.50)$ & $4.01(5.41)$ & $5.69(7.43)$ & $4.62(6.60)$ \\
\hline and title & $\begin{array}{l}\text { Dummy ( } 1 \text { if farmer holds a formal title or registration of cultivated land; } 0 \text { if } \\
\text { otherwise) }\end{array}$ & $0.60(0.49)$ & $0.53(0.50)$ & $0.87(0.33)$ & $0.67(0.47)$ \\
\hline \multirow[t]{2}{*}{ lot distance } & Plot distance to the nearest market $(\mathrm{km})$ & $4.05(2.72)$ & $\begin{array}{c}4.02 \\
(2.81) \\
\end{array}$ & $3.64(2.86)$ & $3.91(2.79)$ \\
\hline & \multicolumn{5}{|l|}{ Location level covariates } \\
\hline abour price & Average price of labour in the village (USD) & $\begin{array}{c}12.61 \\
(126.35)\end{array}$ & $\begin{array}{c}176.54 \\
(479.29)\end{array}$ & $\begin{array}{c}31.74 \\
(149.12)\end{array}$ & $\begin{array}{c}61.94 \\
(281.04) \\
\end{array}$ \\
\hline \multirow[t]{2}{*}{$\begin{array}{l}\text { ertilizer } \\
\text { rice }\end{array}$} & Average price of fertilizer in the village (USD) & $\begin{array}{c}15.78 \\
(51.81) \\
\end{array}$ & $\begin{array}{c}53.63 \\
(115.76)\end{array}$ & $\begin{array}{c}31.54 \\
(71.08) \\
\end{array}$ & $\begin{array}{c}30.82 \\
(80.60) \\
\end{array}$ \\
\hline & \multicolumn{5}{|c|}{$\begin{array}{ll}\text { Institutional level covariates } \\
\end{array}$} \\
\hline $\begin{array}{l}\text { ontract } \\
\text { irming }\end{array}$ & Dummy ( 1 if contract farming scheme is available in the village; 0 if otherwise) & $0.72(0.45)$ & $0.71(0.45)$ & $0.52(0.50)$ & $0.66(0.48)$ \\
\hline redit & $\begin{array}{l}\text { Dummy ( } 1 \text { if credit is available for staple crop production for farmers in the village; } \\
0 \text { if otherwise) }\end{array}$ & $0.26(0.44)$ & $0.12(0.32)$ & $0.12(0.32)$ & $0.18(0.38)$ \\
\hline \multirow[t]{2}{*}{$\begin{array}{l}\text { larket } \\
\text { atlet }\end{array}$} & Dummy (1 if produce is sold at farm-gate; 0 if otherwise & $0.14(0.34)$ & $\begin{array}{c}0.34 \\
(0.47) \\
\end{array}$ & $0.39(0.49)$ & $0.27(0.45)$ \\
\hline & \multicolumn{5}{|l|}{$\begin{array}{ll} & \text { Instruments } \\
\end{array}$} \\
\hline erception & Dummy ( 1 if the technologies relevant or yield enhancing; 0 if otherwise) & $0.19(0.39)$ & $\begin{array}{c}0.12 \\
(0.33)\end{array}$ & $0.22(0.41)$ & $0.18(0.39)$ \\
\hline xtension & Dummy ( 1 if farmer received advice from extension staff; 0 if otherwise) & $0.52(0.50)$ & $\begin{array}{c}0.62 \\
(0.49)\end{array}$ & $0.43(0.50)$ & $0.52(0.50)$ \\
\hline$\overline{\mathrm{BO}}$ & $\begin{array}{l}\text { Dummy ( } 1 \text { if farmer is a member of any local farmer organization dealing with } \\
\text { agriculture; } 0 \text { if otherwise) }\end{array}$ & $0.28(0.45)$ & $\begin{array}{c}0.31 \\
(0.46) \\
\end{array}$ & $0.35(0.48)$ & $0.31(0.46)$ \\
\hline bservations & & 1579 & 1003 & 1227 & 3809 \\
\hline
\end{tabular}

Note that figures in brackets are standard deviations

Table 3: Descriptive Statistics by Adoption of SAPs 


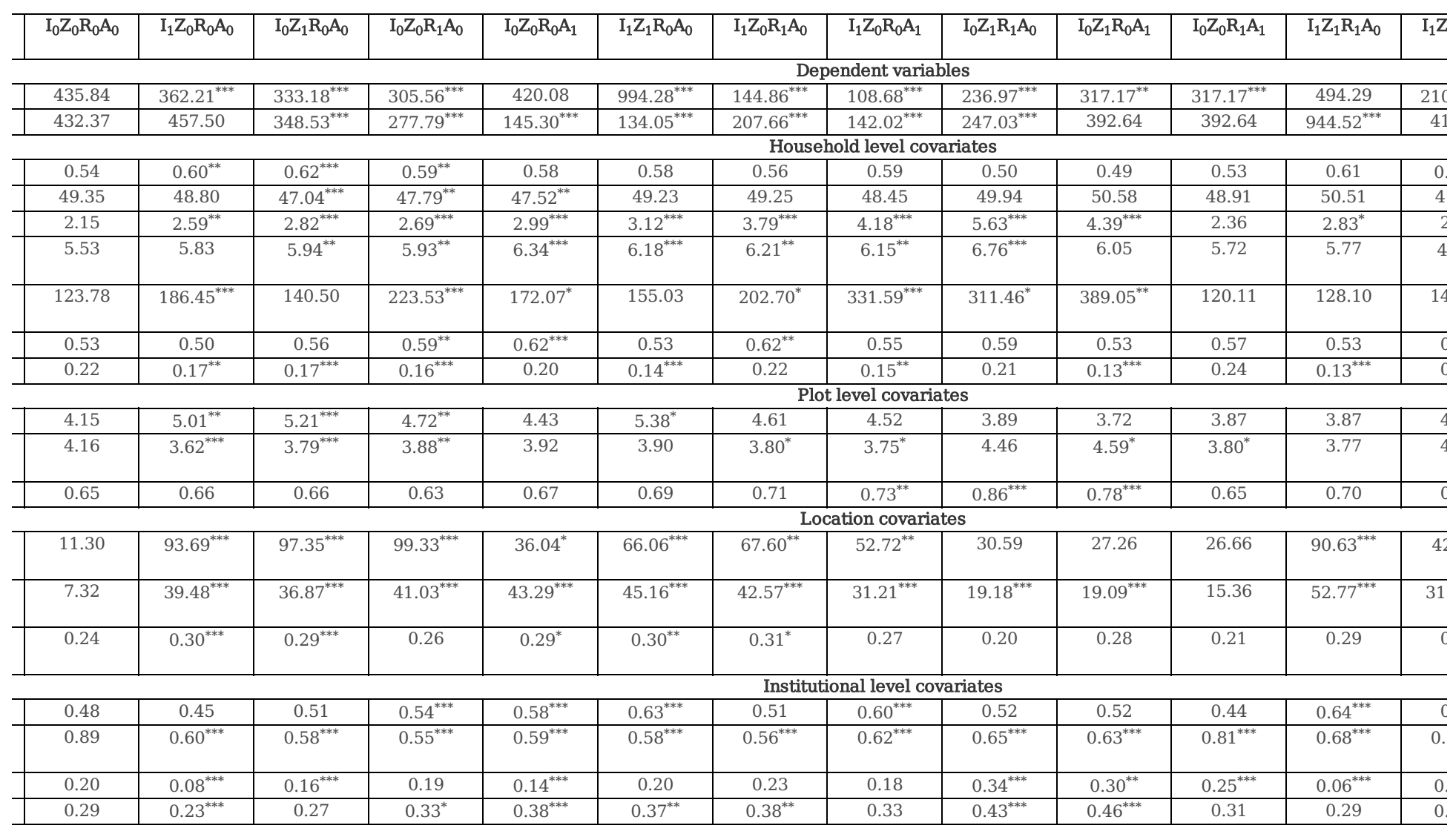

Note: Means of explanatory variables between each plan package (adopters) and no plan package $\left(\mathrm{I}_{0} \mathrm{Z}_{0} \mathrm{R}_{0} \mathrm{~A}_{0}\right)$ are compared using t-test.*p<0.1; $* * \mathrm{p}<0.5 ; * * * \mathrm{p}<0.001$.

[1]We are aware of the potential endogeneity of income from off-farm employment. For this reason, observed values of off-farm income activities and their corresponding residuals from the first stage regression was incorporated into the main estimations. The results were, however, not significant and are not presented for purpose of brevity.

[2] $T C=[(M P * 0.90 * 0.97)+(S P * 0.90 * 0.97)+(R P * 0.65 * 0.99)+(C P * 0.85)$ with $0.90,0.90,0.65$ and 0.85 as the milling ratios for millet, sorghum, rice and maize respectively and $0.97,0.97$ and 0.99 as the maize equivalent of millet, sorghum and rice on a milled basis respectively (Jolly \& Gadbois, 1996).

\section{Results}

This section presents the results of the impacts of SAPs on FI and FS. Since the primary objective is to examine the FI and FS impact of SAPs, the results of determinants of adoption of SAPs are presented in Table A1 of the appendix[3]. Also, the impact of control variables on FI and FS (self-sufficiency in food production-SSF) are not presented due to space limitation but are available upon request. Two issues are worth mentioning in Table A1. First, the Wald test in the pooled sample is significant, indicating that the regression coefficients jointly affect adoption of SAPs. The results also support the validity of the instruments used, as indicated by their significance in the adoption equations but not in the outcome equations (Tables A2-A5). Second, the results show that household, plot, location, and institutional variables are important in explaining the behaviour of rural household in the adoption of the SAPs in Africa. However, these variables differ across the three regions considered in this study. The Hausman test (as presented in Tables A6-A8 in the appendix) also shows that the assumption of Independence of Irrelevance Alternatives (IIA) among the various SAPs was not violated. In the next subsections, the METE, DRF and MTE estimates of FI and SSF impacts of SAPs are presented. Unlike the estimations in Tables 2 and 3 , the estimations from these models control for confounding factors that might bias the results.

\subsection{Impact of SAPs on farm income and food security}

The impact of SAPs on FI and SSF are presented in Table 4. Most of the coefficients on the factor loadings in the FI and SSF equations are negative and significant in the pooled sample and in all the regions (East, West, and Southern Africa), indicating that the use of the METE model in accounting for selection bias is appropriate. The significance of implies that unobserved variables that enhance the probability of adoption of SAPs might also decrease/increase FI and SSF in the sample and in all the three regions.

Generally, the estimates show significant effects of the practices on both FI and FS in the pooled sample and in each region. In particular, adopting intercropping with nitrogen fixing crops $\left(I_{1} Z_{0} R_{0} A_{0}\right)$ in isolation significantly decreased average $\mathrm{FI}$ and $\mathrm{SSF}$ in the pooled sample and in all the regions. However, the decrease in both outcomes is higher in East Africa; $29 \%$ and $33 \%$ for FI and SSF, respectively. Also, adoption of zero tillage only $\left(I_{0} Z_{1} R_{0} A_{0}\right)$ is associated with $27 \%$ and $48 \%$ decrease in $\mathrm{FI}$ and SSF, respectively, relative to non-adopters. As can be observed in Table 4 , the decrease is significantly higher among farm households in Southern Africa (FI-49\% and SSF-80\%).

The results further demonstrated that the adoption of two SAPs at the same time led to decrease in both FI and FS across all regions. For instance, both FI and SSF decreased significantly in the pooled sample and in all the regions for adopting intercropping with either zero tillage, residue incorporation or animal 
manure. However, the decrease in FI is significantly higher in Southern Africa and ranged between $86 \%$ and $90 \%$ while that of SSF is higher in East Africa and ranged between $71 \%$ and $88 \%$ when intercropping is combined separately with zero tillage, crop residue incorporation and animal manure. Similarly, household Fl decreased for adopting zero tillage with either residue incorporation or animal manure or adopting the latter two simultaneously in a plan. These suggest that adopting only two of these practices might not be economically rational in terms of FI and FS. However, FI and FS increased significantly for adopting three or more SAPs at the same time. In particular, average $\mathrm{FI}$ and SSF increased in all the regions and in the pooled sample for households that simultaneously adopted intercropping, zero tillage and residue incorporation $\left(\mathrm{l}_{1} \mathrm{Z}_{1} \mathrm{R}_{1} A_{0}\right)$ for crop production.

It is also observed that the impact of adoption of three or more SAPs on FI appeared to be higher in West Africa while impact on FS is more pronounced in Southern Africa. Specifically, the average FI increased by $41 \%$ in West Africa while that SSF increased by $98 \%$ in Southern Africa due to simultaneous adoption of these practices $\left(I_{1} Z_{1} R_{1} A_{0}\right)$. In East Africa, the adoption of intercropping, zero tillage and animal manure $\left(I_{1} Z_{1} R_{0} A_{1}\right)$ in combination resulted in $86 \%$ significant increase in $\mathrm{Fl}$, while the adoption of the same combination led to a greater effect on food security (i.e., 78\% increase SSF) in West Africa. These results are consistent with earlier studies in Zambia on adoption of conservation agricultural practices (Manda et al., 2016). Interestingly, the results also show that adopting all the practices (i.e., $\mathrm{l}_{1} \mathrm{Z}_{1} \mathrm{R}_{1} \mathrm{~A}_{1}$ ) significantly increased $\mathrm{Fl}$ by $49 \%$ in East Africa, $82 \%$ in West Africa, $48 \%$ in Southern Africa and in $50 \%$ in the pooled sample, as well as SSF by $59 \%$ and $50 \%$ for East Africa and the pooled sample, respectively. This corroborates with previous studies which found that adoption of complete packages of SAPs improves households welfare in Africa (e.g., Abdallah et al., 2020; Sardar et al., 2020; Tesfaye et al., 2020).

Table 4: METE model estimation results of adoption impact in Africa

\begin{tabular}{|c|c|c|c|c|c|c|c|c|}
\hline Plan & \multicolumn{2}{|c|}{ East Africa } & \multicolumn{2}{|c|}{ West Africa } & \multicolumn{2}{|c|}{ Southern Africa } & \multicolumn{2}{|c|}{ Pooled sample } \\
\hline & FI & SSF & FI & SSF & FI & SSF & FI & SSF \\
\hline $\mathrm{I}_{1} \mathrm{Z}_{0} \mathrm{R}_{0} \mathrm{~A}_{0}$ & $-0.29(0.02)^{* * *}$ & $-0.33(0.16)^{* *}$ & $-0.18(0.09)^{* *}$ & $-0.24(0.12)^{* *}$ & $-0.16(0.08)^{* *}$ & $-0.10(0.20)$ & $-0.20(0.11)^{*}$ & $-0.22(0.04)^{* * *}$ \\
\hline $\mathrm{I}_{0} \mathrm{Z}_{1} \mathrm{R}_{0} \mathrm{~A}_{0}$ & $-0.24(0.13)^{*}$ & $-0.45(0.11)^{* * *}$ & $-0.27(0.13)^{* *}$ & $-0.48(0.25)^{* *}$ & $-0.13(0.15)$ & $-0.09(0.05)^{*}$ & $-0.38(0.21)^{* * *}$ & $-0.18(0.22)^{*}$ \\
\hline $\mathrm{I}_{0} \mathrm{Z}_{0} \mathrm{R}_{1} \mathrm{~A}_{0}$ & $-0.33(0.20)$ & $-0.30(0.33)$ & $0.20(0.15)$ & $-0.29(0.25)$ & $0.33(0.41)$ & $-0.24(0.25)$ & $-0.32(0.20)$ & $-0.19(0.15)$ \\
\hline $\mathrm{I}_{0} \mathrm{Z}_{0} \mathrm{R}_{0} \mathrm{~A}_{1}$ & $-0.36(0.12)^{* * *}$ & $-0.30(0.15)^{* *}$ & $-0.35(0.13)^{* * *}$ & $-0.49(0.21)^{* *}$ & $-0.49(0.21)^{* * *}$ & $-0.80(0.40)^{* *}$ & $-0.39(0.18)^{* * *}$ & $-0.41(0.10)^{* * *}$ \\
\hline $\mathrm{I}_{1} \mathrm{Z}_{1} \mathrm{R}_{0} \mathrm{~A}_{0}$ & $-0.50(0.16)^{* * *}$ & $-0.85(0.21)^{* * *}$ & $-0.47(0.16)^{* * *}$ & $-0.36(0.11)^{* * *}$ & $-0.88(0.16)^{* * *}$ & $-0.13(0.03)^{* * *}$ & $-0.53(0.23)^{* * *}$ & $-0.88(0.55)^{* * *}$ \\
\hline $\mathrm{I}_{1} \mathrm{Z}_{0} \mathrm{R}_{1} \mathrm{~A}_{0}$ & $-0.56(0.15)^{* * *}$ & $-0.71(0.36)^{*}$ & $-0.49(0.24)^{* *}$ & $-0.42(0.70)$ & $-0.86(0.11)^{* * *}$ & $-0.46(0.31)$ & $-0.48(0.24)^{*}$ & $-0.44(0.23)^{*}$ \\
\hline $\mathrm{I}_{1} \mathrm{Z}_{0} \mathrm{R}_{0} \mathrm{~A}_{1}$ & $-0.76(0.10)^{* * *}$ & $-0.80(0.13)^{* * *}$ & $-0.51(0.17)^{* * *}$ & $0.43(0.98)$ & $-0.90(0.17)^{* * *}$ & $-0.61(0.34)$ & $-0.62(0.26)^{* * *}$ & $-0.63(0.69)^{* * *}$ \\
\hline $\mathrm{I}_{0} \mathrm{Z}_{1} \mathrm{R}_{1} \mathrm{~A}_{0}$ & $-0.53(0.29)$ & $-0.88(0.49)$ & $-0.50(0.24)^{* *}$ & $0.15(1.38)$ & $-0.55(0.43)$ & $-0.87(0.53)$ & $-0.98(0.36)^{* * *}$ & $-0.39(0.25)^{*}$ \\
\hline $\mathrm{I}_{0} \mathrm{Z}_{1} \mathrm{R}_{0} \mathrm{~A}_{1}$ & $-0.61(0.18)^{* * *}$ & $-0.15(0.18)$ & $-0.57(0.18)^{* * *}$ & $-0.50(0.70)$ & $-0.61(0.18)^{* * *}$ & $0.40(0.42)$ & $-0.43(0.21)^{* *}$ & $-0.27(0.87)$ \\
\hline $\mathrm{I}_{0} \mathrm{Z}_{0} \mathrm{R}_{1} \mathrm{~A}_{1}$ & $-0.28(0.16)^{*}$ & $-0.23(0.78)$ & $-0.27(0.14)^{*}$ & $0.55(0.35)$ & $0.28(0.16)^{*}$ & $0.31(0.30)$ & $0.22(0.18)$ & $0.51(0.2)$ \\
\hline $\mathrm{I}_{1} \mathrm{Z}_{1} \mathrm{R}_{1} \mathrm{~A}_{0}$ & $0.18(0.18)$ & $0.41(0.22)^{*}$ & $0.41(0.18)^{* * *}$ & $0.83(0.30)^{* * *}$ & $0.20(0.18)$ & $0.98(0.29)^{* * *}$ & $0.19(0.20)$ & $0.98(0.70)$ \\
\hline $\mathrm{I}_{1} \mathrm{Z}_{1} \mathrm{R}_{0} \mathrm{~A}_{1}$ & $0.86(0.23)^{* * *}$ & $0.32(0.17)^{*}$ & $0.85(0.43)^{*}$ & $0.78(0.39)^{* *}$ & $0.84(0.23)^{* * *}$ & $0.31(0.36)$ & $0.85(0.45)^{*}$ & $0.88(0.88)$ \\
\hline $\mathrm{I}_{1} \mathrm{Z}_{0} \mathrm{R}_{1} \mathrm{~A}_{1}$ & $0.63(0.32)^{*}$ & $0.09(0.02)^{* * *}$ & $0.41(0.25)$ & $0.12(0.98)$ & $0.60(0.40)$ & $0.37(0.65)$ & $0.50(0.11)^{* * *}$ & $0.80(0.29)^{* * *}$ \\
\hline $\mathrm{I}_{0} \mathrm{Z}_{1} \mathrm{R}_{1} \mathrm{~A}_{1}$ & $0.61(0.29)^{* * *}$ & $0.49(0.87)$ & $0.14(0.07)^{* *}$ & $0.32(0.98)$ & $0.17(0.29)^{* * *}$ & $0.28(0.15)^{*}$ & $0.25(0.27)^{* * *}$ & $0.33(0.71)^{* * *}$ \\
\hline $\mathrm{I}_{1} \mathrm{Z}_{1} \mathrm{R}_{1} \mathrm{~A}_{1}$ & $0.49(0.15)^{* * *}$ & $0.59(0.26)^{* * *}$ & $0.82(0.27)^{* * *}$ & $0.67(0.34)^{*}$ & $0.48(0.25)^{* * *}$ & $0.97(0.49)^{*}$ & $0.50(0.26)^{*}$ & $0.50(0.22)^{* * *}$ \\
\hline \multicolumn{9}{|c|}{ Selection terms $(\lambda)$} \\
\hline $\mathrm{I}_{1} \mathrm{Z}_{0} \mathrm{R}_{0} \mathrm{~A}_{0}$ & $0.04(0.01)^{* * *}$ & $-0.62(0.20)^{* * *}$ & $0.06(0.03)^{* *}$ & $0.07(0.02)^{* * *}$ & $0.04(0.02)^{*}$ & $-0.05(0.03)^{*}$ & $0.11(0.6)^{* *}$ & $-0.94(0.45)^{* * *}$ \\
\hline $\mathrm{I}_{0} \mathrm{Z}_{1} \mathrm{R}_{0} \mathrm{~A}_{0}$ & $-0.01(0.03)$ & $0.85(0.43)^{*}$ & $-0.11(0.12)$ & $-0.12(0.07)^{*}$ & $-0.11(0.05)^{* *}$ & $-0.02(0.23)$ & $-0.08(0.20)$ & $-0.53(0.27)^{*}$ \\
\hline $\mathrm{I}_{0} \mathrm{Z}_{0} \mathrm{R}_{1} \mathrm{~A}_{0}$ & $0.18(0.09)^{* *}$ & $0.02(0.92)$ & $0.03(0.54)$ & $-0.09(0.04)^{* *}$ & $-0.53(0.74)$ & $0.11(0.06)^{*}$ & $-0.48(0.15)^{* * *}$ & $-0.31(0.56)$ \\
\hline $\mathrm{I}_{0} \mathrm{Z}_{0} \mathrm{R}_{0} \mathrm{~A}_{1}$ & $-0.23(0.12)^{*}$ & $-0.75(0.27)^{* * *}$ & $-0.63(0.23)^{* * *}$ & $-0.01(0.15)$ & $0.13(0.05)^{* *}$ & $0.08(0.02)^{* * *}$ & $-0.28(0.14)^{* *}$ & $-0.96(0.57)^{*}$ \\
\hline $\mathrm{I}_{1} \mathrm{Z}_{1} \mathrm{R}_{0} \mathrm{~A}_{0}$ & $-0.11(0.32)$ & $-0.61(0.18)^{* * *}$ & $-0.31(0.14)^{* * *}$ & $-0.10(0.19)$ & $-0.01(0.01)$ & $-0.05(0.16)$ & $0.12(0.21)$ & $-0.83(0.32)^{* * *}$ \\
\hline $\mathrm{I}_{1} \mathrm{Z}_{0} \mathrm{R}_{1} \mathrm{~A}_{0}$ & $0.01(0.13)$ & $-1.35(0.71)^{*}$ & $-0.16(0.08)^{* *}$ & $-0.06(0.03)^{* * *}$ & $0.40(0.23)^{*}$ & $0.91(0.04)^{* * *}$ & $-0.20(0.12)^{*}$ & $0.75(0.59)$ \\
\hline $\mathrm{I}_{1} \mathrm{Z}_{0} \mathrm{R}_{0} \mathrm{~A}_{1}$ & $0.03(0.09)$ & $-2.39(0.89)$ & $0.10(0.42)$ & $-0.08(0.43)$ & $0.27(0.09)^{* * *}$ & $-0.10(0.26)$ & $-0.87(0.27)^{* * *}$ & $0.66(0.58)$ \\
\hline $\mathrm{I}_{0} \mathrm{Z}_{1} \mathrm{R}_{1} \mathrm{~A}_{0}$ & $-0.02(0.01)^{* *}$ & $-7.09(2.35)^{* * *}$ & $-0.23(0.18)$ & $0.01(0.12)$ & $-0.02(0.23)$ & $0.00(0.00)$ & $0.41(0.31)$ & $0.04(0.10)$ \\
\hline $\mathrm{I}_{0} \mathrm{Z}_{1} \mathrm{R}_{0} \mathrm{~A}_{1}$ & $0.05(0.03)^{*}$ & $-3.67(0.72)$ & $-0.54(0.03)^{* * *}$ & $-0.10(0.08)$ & $-0.05(0.61)$ & $-0.71(0.21)^{* * *}$ & $0.03(0.14)$ & $-0.58(0.56)$ \\
\hline $\mathrm{I}_{0} \mathrm{Z}_{0} \mathrm{R}_{1} \mathrm{~A}_{1}$ & $0.07(0.03)^{* *}$ & $0.99(0.15)^{* * *}$ & $-0.07(0.03)^{* *}$ & $-0.32(0.17)^{* *}$ & $-0.07(0.03)^{* *}$ & $0.12(0.06)^{*}$ & $-0.61(0.13)^{* * *}$ & $-0.91(0.45)^{* *}$ \\
\hline $\mathrm{I}_{1} \mathrm{Z}_{1} \mathrm{R}_{1} \mathrm{~A}_{0}$ & $0.12(0.05)^{* * *}$ & $-5.49(0.87)^{* * *}$ & $0.02(0.03)$ & $-0.20(0.12)^{*}$ & $-0.02(0.13)$ & $-0.38(0.12)^{* * *}$ & $-0.20(0.14)$ & $-0.92(0.20)^{* * *}$ \\
\hline $\mathrm{I}_{1} \mathrm{Z}_{1} \mathrm{R}_{0} \mathrm{~A}_{1}$ & $-0.01(0.03)$ & $-0.36(0.73)$ & $-0.31(0.16)^{*}$ & $0.05(0.01)$ & $-0.11(0.18)$ & $-0.10(0.61)$ & $0.18(0.01)^{* * *}$ & $-1.49(0.58)^{* * *}$ \\
\hline $\mathrm{I}_{1} \mathrm{Z}_{0} \mathrm{R}_{1} \mathrm{~A}_{1}$ & $0.01(0.01)^{*}$ & $0.88(0.09)^{* * *}$ & $-0.09(0.03)^{* * *}$ & $0.03(0.43)$ & $-0.85(0.43)^{* *}$ & $-0.11(0.06)^{*}$ & $-0.38(0.19)^{*}$ & $-0.23(0.12)^{* *}$ \\
\hline $\mathrm{I}_{0} \mathrm{Z}_{1} \mathrm{R}_{1} \mathrm{~A}_{1}$ & $0.14(0.06)^{* * *}$ & $0.47(0.90)$ & $-1.65(0.83)^{*}$ & $-0.45(0.09)^{* * *}$ & $0.04(0.51)$ & $-0.13(0.07)^{* *}$ & $-0.04(0.24)$ & $0.73(0.56)$ \\
\hline $\mathrm{I}_{1} \mathrm{Z}_{1} \mathrm{R}_{1} \mathrm{~A}_{1}$ & $-0.21(0.08)^{* * *}$ & $0.35(0.00)^{* * *}$ & $-0.01(0.03)$ & $-0.01(0.21)$ & $-0.15(0.08)^{*}$ & $0.06(0.06)$ & $0.24(0.13)^{*}$ & $-4.23(1.60)^{* * *}$ \\
\hline
\end{tabular}

The figures in brackets represent standard errors. ${ }^{*} \mathrm{p}<0.1 ; * * \mathrm{p}<0.05 ; * * \mathrm{p}<0.001$

\subsection{Robustness check with Multivalued Treatment Effect Model}

As stated earlier, the Multivalued Treatment Effect (MTE) model (Cattaneo, 2010; Imbens\& Wooldridge, 2009) was estimated to verify consistency of the results. The results are presented in Table A9 in the appendix. Specifically, the effects of adoption of each of the fifteen technologies $(m)$ in package relative to non-adoption (I) of any of the technologies were estimated. Two important assumptions drive the efficiency of the outputs from the MTE model and are worth noting. The first is the CIA and the second is the overlap assumption. For CIA, several studies (Cattaneo, 2010; Imbens \& Wooldridge, 2009) argue that given a rich set of data, a balance of differences in covariates can lead to accurate estimates of treatment effects. Thus, given the richness of the dataset employed in this study, it is believed that the probability of meeting CIA will be extremely high. With respect to the overlap assumption, a graph of the density distributions of the estimated probabilities of receiving each treatment was plotted. As can be observed in Figure A1, the estimated densities have little mass around 0 or 1 , indicating that the assumption is met. 
The results of the MTE model (Table A9) are similar to that of the multinomial endogenous treatment effects model, except that the average treatment effects (ATEs) are higher and differ by location. The results confirm that adoption of intercropping in isolation led to a decrease in farm income and household food security in all the regions. However, higher farm income and food security (i.e., SSF) effects are associated with joint adoption of the practices suggesting complementarily in practices.

\subsection{Assessing impacts of SAPs using Dose Response Functions}

Further, a dose-response functions (DRF) and the marginal treatment effect functions were estimated to assess the impact of adoption (within the context of continuous treatment) on the outcome variables, following Guardabascio and Ventura (2014). The results from the DRF revealed U-shape curves (Figures A2A7 of the appendix) [4] for the relationship between treatment level and both FI and SSF. This suggests that both FI and FS declined with lower number of SAPs (1-2). However, the impact on FI and SSF production started to increase with adoption of higher number of practices (3-4 SAPs), confirming the results from the multinomial endogenous treatment effect model. This decline probably occurred when adoption was at most two practices while the increase occurred when adoption was at least three practices (i.e., Figures A2-A7 of the appendix). For instance, decrease in average FI ranged from US\$5.40 to US\$4.80 in East Africa (Figure A2), US\$5.25 to US\$5.10 in West Africa (Figure A3) when adoption level was at most two practices, but decreased from US\$4.70/ha to US\$3.25/ha in Southern Africa (Figure A4) when adoption level was at most three practices. On the other hand, the decrease in SSF ranged from US\$5.20/ha to US\$4.50/ha in East Africa (Figure A5), US\$5.20/ha to US\$4.80/ha in West Africa (Figure A6) and US\$5.10/ha to US\$4.50/ha in Southern Africa (Figure A7) when adoption level is at most two practices. However, FI increased from US\$4.90/ha to US\$6.40/ha in East Africa and US\$5.10/ha to US\$5.40/ha in West Africa for adopting more that than two practices. Nevertheless, in Southern Africa, the increase is experienced for adopting more than three practices, and this ranged from US\$3.25/ha to US\$4.25/ha. Similar pattern of results was observed for the marginal treatment effects (the right panel of figs. A2-A7).

[3]The results in this Table are not discussed due to space limitation.

[4]For lack of space the plots of dose-response functions (DRF) are presented in figures A2-A7 in the Appendix

\section{Discussion}

In terms of FI and SSF, the findings revealed significant differences between farm households cultivating with SAPs and those without SAPs. Specifically, households adopting SAPs in isolation or combining at most two practices experience a decrease in both FI and SSF as compared to their non-adopting counterparts in Africa. However, a positive improvement in FI and SSF is realized when farm households adopt at least three SAPs in combination. Interestingly, these findings are consistent in all the models employed for the analysis and thus suggest that adopting complete package of SAPs increases FI and FS than partial adoption. Even though the results are striking, they are plausible for several reasons. First, most production systems are faced with several challenges including soil erosion, poor soil organic matter and pests (Teklewold et al., 2013b). Under such conditions, SAPs may have to reduce soil erosion, improve organic matter, improve fertility, increase yields and consequently, farm income and food security over time. Binswanger and Pingali (1988) for example explained that some agricultural technologies may control erosion over long period of time and hence may not increase yields immediately after adoption. Given such caveats, the benefits of some SAPs packages will not be immediate and may be realized over time, and hence may not increase FI and FS in early years of adoption. Second, the role of every SAP is specific and may therefore contribute to higher impacts when adopted with interrelated technologies (Abdallah et al., 2020; Kassie et al., 2018). Thus, the adoption of intercropping, zero-tillage, residue incorporation and animal manure in isolation may not increase FI or FS unless complete combination is adopted. These explanations probably show why Fl, and FS decrease with individual or combined adoption of at most two practices but increase when at least three practices are combined. The results agree with the argument that the adoption of SAPs in combination improves household's welfare as compared to adoption in isolation. Kassie et al. (2018) in particular argued that every technology performs better when adopted with interrelated technologies or complemented with other technologies. The current study also confirms the findings by Abdallah et al. (2020) who found that adoption of intercropping with zero-tillage, residue incorporation and animal manure use improve household welfare in Africa. The results also confirm the findings of some recent studies which demonstrate household welfare improvement due to adoption of SAPs (e.g., Manda et al., 2016).

The results further agrees with the claims that adoption impacts can vary across different locations of Africa (Binswanger \& Pingali, 1988). For instance, whereas significant increase in $\mathrm{Fl}$ is observed in the adoption of intercropping with zero tillage and residue retention $\left(I_{1} Z_{1} R_{1} A_{0}\right)$ in West $A f r i c a$, the same is not observed in East and Southern Africa. On the converse, the highest increase in FS is observed in Southern Africa. This is followed by West and East Africa respectively, for adoption of the same practice (i.e., $I_{1} Z_{1} R_{1} A_{0}$ ). Indeed, intercropping with zero tillage and residue retention may be cost-effective and profitable in densely populated areas than in sparsely populated areas. Thus, the response of FI and FS to such farm strategy is likely to vary for regions with different population density. This probably explains the variations in FI and FS for West, East and Southern Africa. This finding is however in conformity with a study by Abdallah et al. (2020) in which the impacts of SAPs was found to vary across different locations of Africa. Similar results are observed by Tambo and Mockshell (2018) where SAPs were found to vary considerably among different countries.

\section{Policy And Managerial Implications}

These findings have important policy implications for scaling up and promoting sustainable agriculture in Africa. Firstly, the negative effects of some SAPs adopted in single or lower levels of combination could imply that farmers might only derive economic benefits from adoption if they are assisted to adopt the right number of practices as a package. Secondly, some SAPs need time to produce positive dividends and the effect of adoption might be negative in the short term. Thus, SAPs such as zero-tillage, residue incorporation and animal manure might require more than one farming season to produce benefits. However, this study did not capture the long-term effects in our analysis due to data limitation. Despite this caveat, the findings of this study signify the 
complementarity effects of sustainable agricultural practices and therefore policy efforts that lead to promotion of complete package adoption would enhance higher farm incomes and food security in Africa. This study calls for the promotion of complete adoption packages whose components are complementary to ensure better adoption outcomes in Africa. However, while promoting complete adoption of SAPs packages, compatibility of SAPs with the different locations should also be taken into consideration.

\section{Conclusions}

This study examined the impact of multiple adoption of sustainable agricultural practices (SAPs) - intercropping with nitrogen fixing crops, zero tillage, residue incorporation and animal manure use - on farm income and food security (i.e., self-sufficiency in food production) among rural households in Africa, using cross-sectional data from Africa's intensification of food crops project. Due to nonrandom assignment of SAPs adoption to households, the causal impact of the SAPs is estimated by utilizing multinomial endogenous treatment effect model. Additionally, the multivalued treatment effects model and dose-response functions are estimated for robustness checks.

The findings revealed that adoption of one or two SAPs led to significant reduction in farm income and food security in Africa. Conversely, adoption of three or more SAPs in combination significantly increased in farm income and food security in Africa. Based on these insights, it is concluded that significant improvement in household welfare would be realized when the appropriate packages of SAPs are combined by households in Africa.

The results also revealed significant variation of farm income and food security across different locations of Africa (Western, Eastern and Southern Africa) for adoption of the different combination of SAPs. Rural households in Southern Africa experience the greatest impact on food security when all the four SAPs are jointly adopted. In addition, the impact of adoption on farm income was highest among farm households in West Africa. On the basis of such revelation, this study concludes that the benefits of SAPs depend on the different locations in Africa.

\section{Declarations}

Competing interests: The authors declare no competing interests.

\section{References}

Abdallah, A.-H. (2017). Determinants of adoption of soil and water and conservation techniques: evidence from Northern Ghana. Int. J. Sustainable Agricultural Management and Informatics, 3(1), 31-43.

Abdallah, A.-H., Abdul-Rahaman, A., \& Issahaku, G. (2020). Production and hidden hunger impacts of sustainable agricultural practices: evidence from rural households in Africa. Agrekon, 59(4), 440-458.

Abdul-Rahaman, A., Issahaku, G., \& Zereyesus, Y. A. (2021). Improved rice variety adoption and farm production efficiency: Accounting for unobservable selection bias and technology gaps among smallholder farmers in Ghana. Technology in Society, 64(November 2020), 101471.

Abdulai, A. (2018). Simon Brand Memorial Address. The challenges and adaptation to climate change by farmers in Sub-Saharan Africa. Agrekon, 57(1), 112.

Annan, K., \& Dryden, S. (2015). Food and the transformation of Africa: Getting smallholders connected. Foreign Affairs, 94(6), $124-129$.

AU Summit-Malabo. (2014). Malabo Declaration on Accelerated Agricultural Growth and Transformation for Shared Prosperity and Improved Livelihoods. African Union, 1 (Xxiii), 1-7.

Barbier, E. B., \& Hochard, J. P. (2018). The impacts of climate change on the poor in disadvantaged regions. Review of Environmental Economics and Policy, $12(1), 26-47$.

Binswanger, H., \& Pingali, P. (1988). Technological Priorities for Farming in Sub-Saharan Africa. The World Bank Research Observer, 3(1), 81-98.

Bourguignon, F., Fournier, M., \& Gurgand, M. (2007). Selection Bias Corrections Based on the Multinomial Logit Model: Monte Carlo Comparisons. Journal of Economic Surveys, 21(1), 174-205.

Cattaneo, M. D. (2010). Efficient semiparametric estimation of multi-valued treatment effects under ignorability. Journal of Econometrics, 155(2), $138-154$.

D’Souza, G., Cyphers, D., \& Phipps, T. (1993). Factors influencing the adoption of sustainable agricultural practices. Agricultural and Resource Economics Review, 22(2), 159-165.

Deb, P. \& Trivedi, P. K. (2006). Maximum simulated likelihood estimation of a negative binomial regression model with multinomial endogenous treatment. The Stata Journal, 6(2), 246-255.

Deb, P., \& Trivedi, P. K. (2006). Specification and simulated likelihood estimation of a non-normal treatment-outcome model with selection: Application to health care utilization. Econometrics Journal, 9(1), 307-331.

Di Falco, S., \& Veronesi, M. (2014). Managing Environmental Risk in Presence of Climate Change: The Role of Adaptation in the Nile Basin of Ethiopia. Environmental and Resource Economics, 57(4), 553-577. 
Dillon, B., \& Barrett, C. B. (2017). Agricultural factor markets in Sub-Saharan Africa: An updated view with formal tests for market failure. Food Policy, 67(2), 64-77. https://doi.org/10.1016/j.foodpol.2016.09.015

Ehiakpor, D. S., Danso-Abbeam, G., \& Mubashiru, Y. (2020). Adoption of interrelated sustainable agricultural practices among smallholder farmers in Ghana. Land Use Policy, 101(June), 105142.

Erenstein, O. (2006). Intensification or extensification? Factors affecting technology use in peri-urban lowlands along an agro-ecological gradient in West Africa. Agricultural Systems, 90(2), 132-158. https://doi.org/10.1016/j.agsy.2005.12.005

FAO. (1989). Sustainable Development and Natural Resources Management. Twenty-Fifth Conference, (Paper C 89 / 2 - Supplement 2), 2-562. FAO, Rome.

Feder, G., Just, R. E., \& Zilberman, D. (1985). Adoption of Agricultural Innovations in Developing Countries: A Survey. Economic Development and Cultural Change, 33(2), 255-298.

Fontes, F. P. (2020). Soil and Water Conservation technology adoption and labour allocation: Evidence from Ethiopia. World Development, $127(3), 104754$.

Greene, W. H. (2002). Econometric Analysis (5th ed.; R. Banister, P. J. Boardman, G. Soto, M. McHale, C. Regan, \& M. Reynolds, Eds.). New Jersey: Prentice Hall. Guardabascio, B., \& Ventura, M. (2014). Estimating the dose-response function through a generalized linear model approach. The Stata Journal, 14(1), 141158.

Imbens, G. W., \& Wooldridge, J. M. (2009). Recent Developments in the Econometrics of Program Evaluation. Journal of Economic Literature, 47(1), 5-86. https://doi.org/10.1257/jel.47.1.5

Issahaku, G., \& Abdulai, A. (2019). Can Farm Households Improve Food and Nutrition Security through Adoption of Climate-smart Practices? Empirical Evidence from Northern Ghana. Applied Economic Perspectives and Policy, 1-22. https://doi.org/10.1093/aepp/ppz002

Jack, B. K. (2013). Market inefficiencies and the adoption of agricultural technologies in developing countries. In White paper, Agricultural Technology Adoption Initiative. Berkeley.

Jolly, C. M., \& Gadbois, M. (1996). The effect of animal traction on labour productivity and food self-sufficiency: The case of Mali. Agricultural Systems, 51(4), $453-467$.

Kassie, M., Marenya, P., Tessema, Y., Jaleta, M., Zeng, D., Erenstein, O., \& Rahut, D. (2018). Measuring Farm and Market Level Economic Impacts of Improved Maize Production Technologies in Ethiopia: Evidence from Panel Data. Journal of Agricultural Economics, 69(1), 76-95.

Kassie, M., Teklewold, H., \& Jaleta, M. (2015). Understanding the adoption of a portfolio of sustainable intensification practices in eastern and southern Africa. Land Use Policy, 42(1), 400-411.

Kirui, O. K., \& Mirzabaev, A. (2015). Drivers of land degradation and adoption of multiple sustainable land management practices. International Conference of Agricultural Economists (ICAE), Agriculture in the Interconnected World, 1-61. Retrieved from https://ageconsearch.umn.edu/bitstream/212008/2/KiruiDrivers of land degradation and adoption of multiple sustainable land management practices-1021.pdf (Accessed on 08/01/2021)

Lele, U., Masters, W. A., Kinabo, J., Meenakshi, J. V., Ramaswami, B., Tagwireyi, J., ... Goswami, S. (2016). Measuring Food and Nutrition Security: An Independent Technical Assessment and User's Guide for Existing Indicators.

Makate, C., Makate, M., \& Mango, N. (2017). Sustainable agriculture practices and livelihoods in pro-poor smallholder farming systems in southern Africa. African Journal of Science, Technology, Innovation and Development, 9(3), 269-279.

Manda, J., Alene, A. D., Gardebroek, C., Kassie, M., \& Tembo, G. (2016). Adoption and Impacts of Sustainable Agricultural Practices on Maize Yields and Incomes: Evidence from Rural Zambia. Journal of Agricultural Economics, 67(1), 130-153.

Morugán-Coronado, A., Linares, C., Gómez-López, M. D., Faz, Á., \& Zornoza, R. (2020). The impact of intercropping, tillage and fertilizer type on soil and crop yield in fruit orchards under Mediterranean conditions: A meta-analysis of field studies. Agricultural Systems, 178(November 2019$), 102736$.

https://doi.org/10.1016/j.agsy.2019.102736

NEPAD. (2003). Comprehensive Africa Agriculture Development Programme. https://doi.org/Website: http//www.nepad.org; E-mail: sundayd@nepad.org; Email: mkandawirer@nepad.org

Pieters, Hannah, Andrea Guariso, \& Vandeplas, A. (2013). Conceptual framework for the analysis of the determinants of food and nutrition security (pp. 1-36). pp. 1-36.

Sanz, M. J., Vente, J. de, Chotte, J.-L., Bernoux, M., Kust, G., Ruiz, I., ... Akhtar-Schuster, M. (2017). Sustainable Land Management contribution to successful land- based climate change adaptation and mitigation. A Report of the Science-Policy Interface. Bonn, Germany.

Sardar, A., Kiani, A. K., \& Kuslu, Y. (2020). Does adoption of climate - smart agriculture ( CSA ) practices improve farmers ' crop income? Assessing the determinants and its impacts in Punjab province, Pakistan. Environment, Development and Sustainability, (0123456789). https://doi.org/10.1007/s10668- 
020-01049-6

Tambo, J. A., \& Mockshell, J. (2018). Differential Impacts of Conservation Agriculture Technology Options on Household Income in Sub-Saharan Africa. Ecological Economics, 151(1), 95-105.

Teklewold, H., Kassie, M., \& Shiferaw, B. (2013). Adoption of multiple sustainable agricultural practices in rural Ethiopia. Journal of Agricultural Economics, 64(3), 597-623.

Teklewold, H., Kassie, M., Shiferaw, B., \& Köhlin, G. (2013). Cropping system diversification, conservation tillage and modern seed adoption in Ethiopia: Impacts on household income, agrochemical use and demand for labor. Ecological Economics, 93, 85-93. https://doi.org/10.1016/j.ecolecon.2013.05.002

Tesfaye, W., Tirivayi, N., Blalock, G., Bageant, L., Boone, C., Mcbride, L., ... Lybbert, T. (2020). Climate-Smart Innovations and Rural Poverty in Ethiopia: Exploring Impacts and Pathways. 00(00), 1-22. https://doi.org/10.1111/ajae.12161

Thomson, A., \& Metz, M. (1998). Implications of Economic Policy for Food Security: A Training Manual. Retrieved March 29, 2021, from Training Materials for Agricultural Planning 40 website: http://www.fao.org/3/X3936E/X3936E03.htm\#self

WFP. (2009). Comprehensive Food Security \& Vulnerability Analysis (CFSVA). Republic of Ghana. Retrieved from www.wfp.org/food-security

Zero Hunger Challenge. (2016). Partnering for Nourishing our People, Nurturing our Planet, Growing Prosperity, Harvesting Peace Transforming our Food Systems to Transform our World Background. Zero Hunger Challenge, 2(6), 1-5.

\section{Figures}

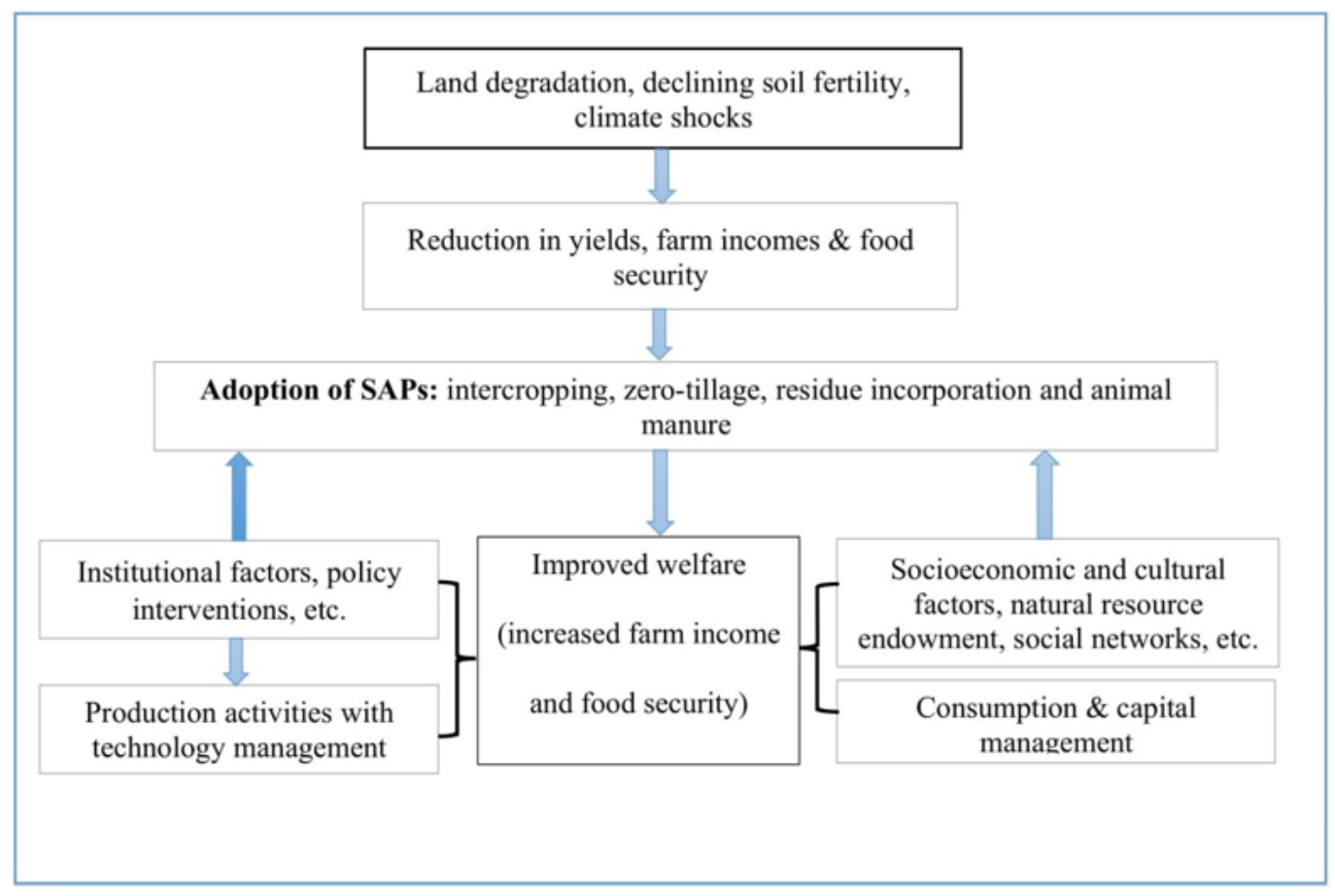

\section{Figure 1}

Conceptual Framework linking SAPs to farm income and food security 


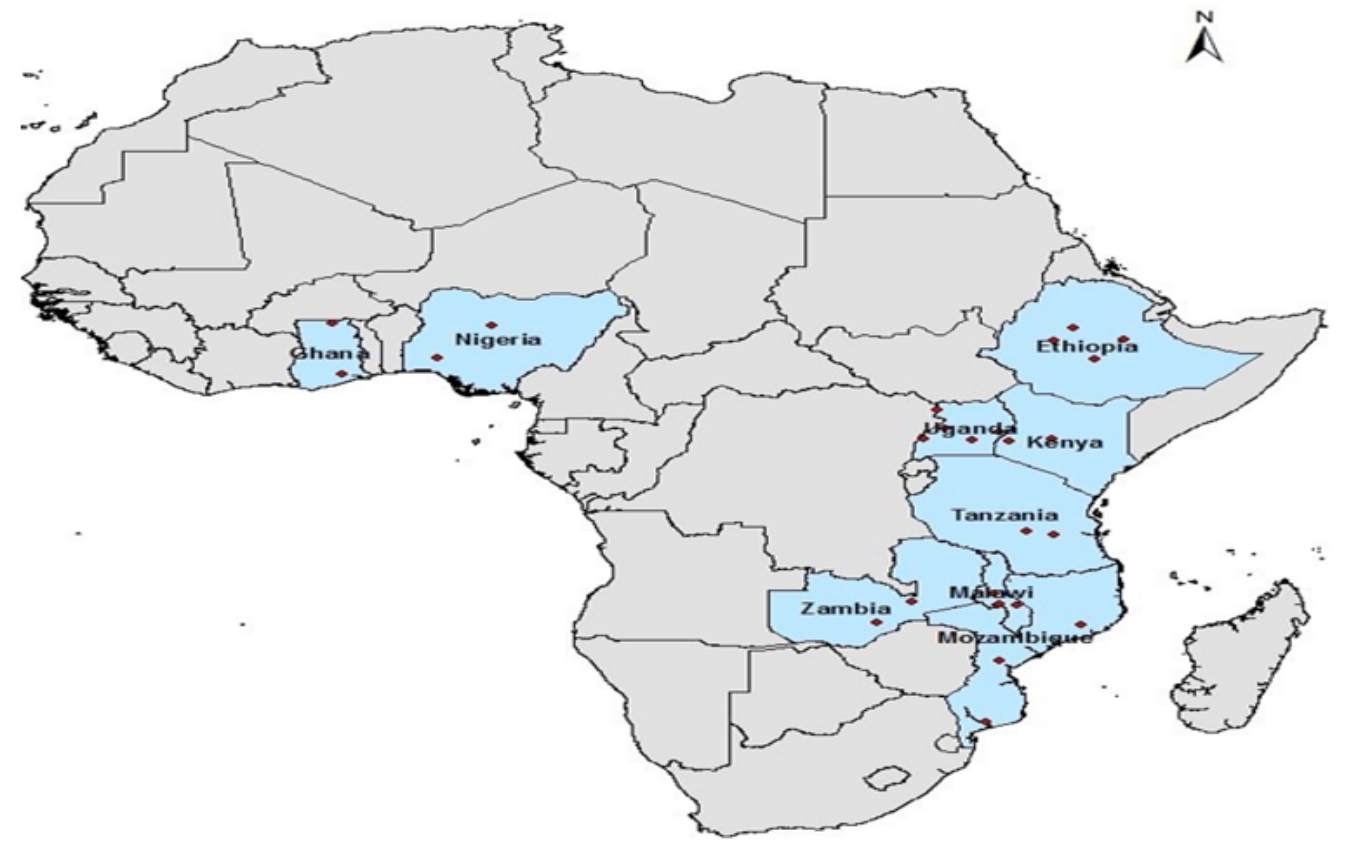

Figure 2

Map showing the study countries and survey regions. Note: The designations employed and the presentation of the material on this map do not imply the expression of any opinion whatsoever on the part of Research Square concerning the legal status of any country, territory, city or area or of its authorities, or concerning the delimitation of its frontiers or boundaries. This map has been provided by the authors.

\section{Supplementary Files}

This is a list of supplementary files associated with this preprint. Click to download.

- Appendices.docx 